\title{
The reproductive hormone cycle of adult female American alligators from a barrier island population
}

\author{
Heather J Hamlin ${ }^{1,2, *}$, Russell H Lowers ${ }^{3,}$, Satomi Kohno ${ }^{1,10}$, Naoko Mitsui-Watanabe ${ }^{4}$, \\ Haruna Amano ${ }^{5,6}$, Akihiko Hara ${ }^{5}$, Yasuhiko Ohta ${ }^{7}$, Shinichi Miyagawa ${ }^{8,9}$, Taisen Iguchi ${ }^{8,9}$ \\ and Louis J Guillette Jr $r^{1,10}$
}

${ }^{1}$ Department of Biology, University of Florida, Gainesville, Florida, USA, ${ }^{2}$ School of Marine Sciences, University of Maine, 5751 Murray Hall, Orono, Maine 04469, USA, ${ }^{3}$ Innovative Health Applications, Kennedy Space Center, Merritt Island, Florida, USA, ${ }^{4}$ Institute of Environmental Ecology, Environmental Risk Research Center, IDEA Consultants, Inc., Yaizu, Shizuoka, Japan, ${ }^{5}$ Faculty of Fisheries Sciences, Hokkaido University, Hokkaido, Japan, ${ }^{6}$ School of Marine Science, Kitasato University, Kanagawa, Japan, ${ }^{7}$ Department of Veterinary Medicine, Faculty of Agriculture, Tottori University, Tottori, Japan, ${ }^{8}$ Department of Basic Biology, Faculty of Life Science, The Graduate School for Advanced Studies (SOKENDAl), Okazaki, Aichi, Japan, ${ }^{9}$ Okazaki Institute for Integrative Bioscience, National Institute for Basic Biology, National Institutes of Natural Sciences, Okazaki, Aichi, Japan and ${ }^{10}$ Hollings Marine Laboratory, Department of Obstetrics and Gynecology, Medical University of South Carolina, Charleston, South Carolina, USA

Correspondence should be addressed to H J Hamlin; Email: heather.hamlin@maine.edu

${ }^{*}(\mathrm{H}$ J Hamlin and R H Lowers contributed equally to this work)

\begin{abstract}
Comparatively, little data are available detailing the geographic variation that exists in the reproductive endocrinology of adult alligators, especially those living in barrier islands. The Merritt Island National Wildlife Refuge (MI) is a unique barrier island environment and home to the Kennedy Space Center (FL, USA). Seasonal patterns of sex steroids were assessed in adult female American alligators from MI monthly from 2008 to 2009, with additional samples collected at more random intervals in 2006, 2007, and 2010. Plasma 17 $\beta$-estradiol and vitellogenin concentrations peaked in April, coincident with courtship and mating, and showed patterns similar to those observed in adult female alligators in other regions. Plasma concentrations of progesterone, however, showed patterns distinctly different than those reported for alligator populations in other regions and remained relatively constant throughout the year. Plasma DHEA peaked in July around the time of oviposition, decreased in August, and then remained constant for the remaining months, except for a moderate increase in October. Circulating concentrations of DHEA have not been previously assessed in a female crocodilian, and plasma concentrations coincident with reproductive activity suggest a reproductive and/or behavioral role. Interestingly, plasma testosterone concentrations peaked in May of 2008, as has been shown in female alligator populations in other regions, but showed no peak in 2009, demonstrating dramatic variability from year to year. Surveys showed 2009 to be particularly depauperate of alligator nests in $\mathrm{MI}$, and it is possible that testosterone could serve as a strong indicator of breeding success.

Reproduction (2014) 147 855-863
\end{abstract}

\section{Introduction}

A great deal has been learned about the reproductive biology of the American alligator (Alligator mississippiensis) in recent decades, fueled in part by increased research efforts following precipitous population declines in the 1960s (Groombridge 1987, Joanen \& McNease 1989, Guillette et al. 1997, Lance et al. 2009). While the majority of American alligators reside in freshwater and have been the focus of much of this research, comparatively little data are available detailing the geographical variation that exists in the reproductive endocrinology of adult alligators, especially of alligator populations living in barrier island locales. The Merritt Island National Wildlife Refuge (MI) is a barrier island environment that provides a variety of habitats, including coastal dunes, saltwater estuaries, open ocean, as well as freshwater impoundments. Established in 1963, MI is also home to the Kennedy Space Center, and the heightened security in this area provides an exceptionally unique opportunity to study a population of alligators that has not experienced hunting pressures and has been fully protected for decades. This barrier island habitat also has a considerable influence on diet, 
and it is not uncommon to find marine prey such as horseshoe crabs (Limulus polyphemus) and blue crabs (Callinectes sapidus) among the stomach contents in these alligators (Nifong et al. 2012, Nifong \& Silliman 2013). Mammals and freshwater fishes make up a considerably smaller percentage of the diet in adult MI alligators than in alligators in exclusively freshwater environments or even alligator populations residing near other marine locales, such as coastal Louisiana (Gabrey 2010).

Freshwater vs marine-based diets vary in nutritional and micronutrient content, and although not yet studied in alligators, diet has been shown to alter reproduction as well as circulating concentrations of sex steroids in a variety of other species, including lizards (Cree et al. 1995, Lovern \& Adams 2008). Hormones direct much of reproduction and gametogenesis and have considerable influence on reproductive behaviors as well (McEwen 1981, Whittier \& Crews 1987, Woolley et al. 2004). While male alligators from MI have been studied extensively (Hamlin et al. 2011), the seasonal reproductive hormone profiles of adult females from this region have yet to be explored.

Studies on adult female alligators carried out in Florida lakes, as well as those carried out near coastal Louisiana, show that courtship and breeding take place in April and May, coincident with elevated concentrations of plasma $17 \beta$-estradiol $\left(E_{2}\right)$ and testosterone and to a lessor extent progesterone $\left(\mathrm{P}_{4}\right)$ (Lance 1989, Guillette et al. 1997, Lance et al. 2009). Eggs are laid in June, which aligns with a rapid decline in plasma $E_{2}$ and testosterone and an elevation in plasma $\mathrm{P}_{4}$ concentration. Approximately $25-68 \%$ of female alligators are reproductively active in a given year, indicating that at least some females do not breed each season, although the reasons and mechanisms for skipping breeding opportunities are not yet clear (Guillette et al. 1997).

The sex steroids $E_{2}, P_{4}$, and testosterone, often show seasonal cyclicity and are highly studied regulators of reproduction in most vertebrates, playing key roles in the production and maturation of gametes (Jones \& Swain 1996, Ott et al. 2000, Edwards \& Jones 2001, Brasfield et al. 2008, Wack et al. 2008, Smith et al. 2010). In female alligators, as with nearly all oviparous vertebrates, $E_{2}$ triggers the hepatic production of vitellogenin (VTG), the primary precursor of egg yolk protein (Ho et al. 1982, Ho 1987, Guillette et al. 1997). VTG serves as the primary energy reserve for developing embryos, and this maternally derived resource relies heavily on proper $E_{2}$ signaling. Plasma $E_{2}$ concentration is highest during vitellogenesis but is lower and relatively constant throughout gravidity and oviposition in alligators (Guillette et al. 1997, Jones 2011). $\mathrm{P}_{4}$ is assumed to be the primary progestin in reptiles (Jones 2011) and peaks during gravidity in female alligators. Plasma concentrations of testosterone vary throughout the breeding season and show peaks during non-reproductive, late vitellogenic, and late gravid stages (Guillette et al. 1997).

DHEA is an androgen found in a variety of animals including mammals, birds, reptiles, and mollusks and is the most abundant circulating steroid in humans (Garstka et al. 1991, Ando et al. 1992, Croll \& Wang 2007). While research on DHEA's role in human health and reproduction has increased dramatically over the past several years (Maninger et al. 2009, Gleicher \& Barad 2011), far less is known regarding its role in other vertebrates, especially wildlife models.

DHEA is secreted primarily by the adrenals and to a lesser extent gonads in humans, some primates and other mammals, and songbirds (Wingfield \& Hahn 1994, Conley et al. 2004, Soma 2006), although its origin has yet to be studied in alligators. That a variety of animals continue to produce DHEA following castration supports an extra-gonadal source (Ando et al. 1988, Pinxten et al. 2003, Soma 2006) and it appears to be present in relatively high concentrations $(\mathrm{ng} / \mathrm{ml}$ range) in both males and females in many species (Balthazart 2010). A specific receptor for DHEA has yet to be discovered, and it is thought to act through a variety of receptors and other signaling mechanisms as well as serve as an intermediate in steroidogenesis (Widstrom \& Dillon 2004, Labrie et al. 2005, Webb et al. 2006).

DHEA is thought to play roles in lipid regulation, immuno-competence, anti-inflammatory responses, neuroprotection, improved cognition, sexual differentiation of the brain (Chin et al. 2008), and in facilitating non-breeding aggression, although specific mechanisms have yet to be determined (Boonstra et al. 2008). In wildlife, the role of DHEA in non-breeding aggression has been studied fairly extensively. Although circulating testosterone increases the aggression needed for territory defense and courting during breeding seasons, it has been associated with reduced immune function and inflammation and it is therefore physiologically costly to maintain elevated concentrations of testosterone for prolonged periods (Ahmed \& Talal 1990, Wilder 1995, Miller \& Hunt 1996, Klein 2000, Moller et al. 2005). Conversely, DHEA has been shown to be immunostimulatory and anti-inflammatory. It is also thought to play key roles in maintaining aggression outside of the breeding season and does so without the physiological costs of testosterone (Grimble 2001, Daynes \& Jones 2002, Poisbleau et al. 2009, Loria \& Ben-Nathan 2011). In male red squirrels (Tamiasciurus hudsonicus), the yearly variation in plasma DHEA concentration is positively correlated with population density and is negatively correlated with testes mass (Boonstra et al. 2008). Male song sparrows are highly territorial even in non-breeding seasons when plasma testosterone concentrations are low, and supplementation with exogenous DHEA increases territorial singing, further supporting its role in facilitating aggression and territorial behaviors (Goodson et al. 2005). 
In adult male American alligators, DHEA shows a seasonal cyclicity in which it peaks in May following significant reductions in testosterone and then declines in June and again in September, but remains relatively stable for the remaining months (Hamlin et al. 2011). Although DHEA is present in both males and females in a wide range of taxa, and its seasonal cyclicity indicates a role in reproduction, it has not yet been investigated in a female crocodilian.

The goal of this study was to determine the seasonal reproductive hormone profiles of adult female American alligators residing in $\mathrm{MI}$, a unique barrier island environment. This study enhances our knowledge of the geographical variation in the endocrinology that underlies reproduction in female American alligators and determines whether alligators from this unique locale demonstrate distinctive patterns that are not yet observed in alligator populations from other regions.

\section{Materials and methods}

\section{Animals and sampling}

Adult female American alligators (A. mississippiensis) were captured under State, Federal and Institutional Animal Care and Use Committee (IACUC) permits and guidelines. Alligators were sampled monthly in 2008 and 2009, with additional samples taken at more random intervals in 2006, 2007, and 2010. Blood samples $(\approx 35 \mathrm{ml})$ were collected from the postcranial supravertebral sinus and were placed into lithium heparin Vacutainer (BD, Franklin, NJ, USA) tubes. Blood was kept on ice until centrifugation at $810 \mathrm{~g}$ for $15 \mathrm{~min}$, and the plasma was stored at $-20{ }^{\circ} \mathrm{C}$ until assayed. Sex was determined by the presence or absence of a penis, and blood samples were collected generally within $10 \mathrm{~min}$ of capture, although no sample took longer than 20 min. Body measurements (total length (TL) and snout vent length (SVL)) were recorded to the nearest centimeter and a numbered monel tag was placed in the webbing of the right hind foot to identify recaptured animals. In addition, a low-frequency internal transponder tag was injected behind the skull, with $100 \%$ retention for recapture verification.

Eggs were collected from Lake Orange (FL, USA) and were incubated and maintained as described previously (Milnes et al. 2005). Egg yolk was collected at developmental stage 19 and was stored at $-80^{\circ} \mathrm{C}$ to use in the development of the VTG assay.

\section{RIAs}

A solid-phase RIA was conducted as described previously (Hamlin et al. 2011). A pool (five animals) of serially diluted alligator plasma was used to ensure parallelism with the standard curve for each hormone. All antibodies were purchased from Fitzgerald Industries (Concord, MA, USA) using the same lot number for each hormone. Plates for the testosterone, $E_{2}$, and $P_{4}$ assay were incubated for $2 \mathrm{~h}$, and plates for the DHEA assay were incubated for $18 \mathrm{~h}$. Interassay variance samples were prepared from a five animal pool of adult alligator plasma samples. Interassay variances for $\mathrm{E}_{2}, \mathrm{P}_{4}$, testosterone, and DHEA averaged 10.7, 9.4, 8.7, and 9.8\% respectively. Intraassay variation was not $>5 \%$.

\section{VTG assay}

Lipovitellin (Lv) was purified from the egg yolk of the American alligator by a combination of water-precipitation and gel filtration according to a method described previously (Hiramatsu \& Hara 1996) with the following modifications. Three grams of egg yolk were homogenized in a ground glass homogenizer (Iwaki, Tokyo, Japan) with $30 \mathrm{ml}$ of $0.02 \mathrm{M}$ Tris$\mathrm{HCl}(\mathrm{pH}$ 9.0) containing $0.5 \mathrm{M} \mathrm{NaCl}$. The egg yolk homogenates were centrifuged (15 000 r.p.m., $20 \mathrm{~min}, 4{ }^{\circ} \mathrm{C}$ ) and the resulting supernatant was collected as alligator egg extracts. The extracts $(\sim 30 \mathrm{ml})$ were precipitated by drop-wise addition into ten times volume $(\sim 300 \mathrm{ml})$ of ice-cold distilled water and stored overnight at $4{ }^{\circ} \mathrm{C}$. Following centrifugation as described above, the resulting precipitate was collected and dissolved in $12 \mathrm{ml}$ Tris- $\mathrm{HCl}$ buffer. Two consecutive gel filtration steps using Sephadex G-200 (GE Healthcare UK Ltd, Little Chalfont, UK) and Superose 6 (GE Healthcare UK Ltd) were performed following the water-precipitation step. The Sephadex G-200 medium was loaded into a $5 \times 90 \mathrm{~cm}$ glass column and equilibrated with Tris-HCl buffer. The water-precipitated yolk fraction $(\sim 7.5 \mathrm{ml})$ was applied onto the column and eluted with Tris- $\mathrm{HCl}$ buffer at a flow rate of $40 \mathrm{ml} / \mathrm{h}$ at $4{ }^{\circ} \mathrm{C}$. Eluted fractions were collected at a volume of $13 \mathrm{ml} /$ tube. Fractions, which contained LV as a dominant yolk protein, were collected, pooled, and subjected to the second gel filtration on a Superose 6 column equilibrated with Tris- $\mathrm{HCl}$ buffer. Elution of the Lv sample was performed using an FPLC system (GE Healthcare UK Ltd) under conditions described previously (Amano et al. 2007). A single peak was observed at the position corresponding to $\sim 410 \mathrm{kDa}$; this peak fraction was collected as purified Lv.

Polyclonal antiserum was raised in the rabbit against purified Lv (anti-Lv) by intradermal injection of each antigen emulsified with an equal volume of Freund's complete adjuvant (Merck). This emulsified Lv was injected into the rabbit $(0.25 \mathrm{mg} /$ injection) four times at weekly intervals. Blood was obtained from the ear vein of the immunized rabbit 1 week after the final injection and used for the preparation of antiserum.

The VTG immunoassay was developed in a format of a competitive ELISA. Wells of 96-well microtiter plates (Maxisorpll, Nunc, Thermo Fisher Scientific (Waltham, MA, USA)) were coated with $50 \mu \mathrm{l}$ PBS solution containing the purified Lv at a concentration of $1 \mu \mathrm{g} / \mathrm{ml}$ at $4{ }^{\circ} \mathrm{C}$ overnight. After washing the plate three times with PBS containing 0.1\% Tween 20 (TPBS), wells were blocked with $300 \mu \mathrm{l}$ of blocking reagent $(0.5 \%$ BlockAce-TPBS). For the standards, plasma of males injected with $0.27 \mathrm{mg} / \mathrm{kg} \mathrm{E}_{2}$ every other day for 12 days was serially diluted in blocking reagent from 1:50 to 1:36 450. In parallel, plasma samples were diluted in blocking reagent. The standards and unknown samples $(60 \mu \mathrm{l} /$ well $)$ were pre-incubated in separate non-coated 96-well microtiter plates (Greiner Japan, Tokyo, Japan) with $\mathrm{Lv}$ antiserum $(60 \mu \mathrm{l} / \mathrm{well}, 0.5 \mu \mathrm{g} / \mathrm{ml}$ in blocking reagent) for $1 \mathrm{~h}$ at room temperature. After washing 
the blocked Lv-coated plate as described above, $50 \mu \mathrm{l}$ of the sample/antiserum or standard/antibody mixtures were transferred into wells of the coated plate from the separate noncoated plate and incubated for $1 \mathrm{~h}$ at room temperature. After the wells were washed as described above, $50 \mu$ l of the HRPlabeled secondary antibody (goat anti-rabbit IgG, Zymed, Life Technologies) was added to each well and incubated for $1 \mathrm{~h}$ at room temperature. After washing the wells as described above, they were filled with $100 \mu$ of a color reaction mixture (TMBZ and TMBZ buffer, Japan EnviroChemicals Ltd, Osaka, Japan). The reactions were carried out for $1 \mathrm{~h}$ at room temperature and stopped by addition of $100 \mu \mathrm{l}$ of $1 \mathrm{M} \mathrm{HCl}$ solution. Absorbance of the reactions was determined at $450 \mathrm{~nm}$ with an ELISA plate reader (SpectraRainbow, Tecan Japan, Kawasaki, Japan). Levels of VTG in plasma samples were relatively quantified considering the VTG concentration of standard plasma as 1 .

\section{Statistical analyses}

Differences in plasma hormone and VTG concentrations among months were analyzed using a one-way ANOVA (Statview Software, version 5.0.1; SAS Institute, Inc. (Cary, NC, USA)). If significant variation $(P<0.05)$ existed, a Fisher protected least significant difference test was performed. Nonhomogenous data sets (determined with $P<0.05$ using Scheffé $F$ test) were log transformed to achieve homogeneity prior to ANOVA analyses, although all figures show untransformed values, with averages given as \pm s.E.M.

\section{Results}

\section{Sampling, morphometric, and environmental data}

A total of 220 adult female alligators were captured from MI from 2006 to 2010. Although data from all animals captured were used in the morphometric regressions shown in Fig. 1, only females with an $\mathrm{SVL} \geq 93 \mathrm{~cm}$ $(183 \mathrm{~cm} \mathrm{TL})$ were classified as adults and included in the hormone evaluations. Monthly averages for temperature $\left({ }^{\circ} \mathrm{C}\right)$ and rainfall $(\mathrm{cm})$ are presented in Fig. 2 . There were

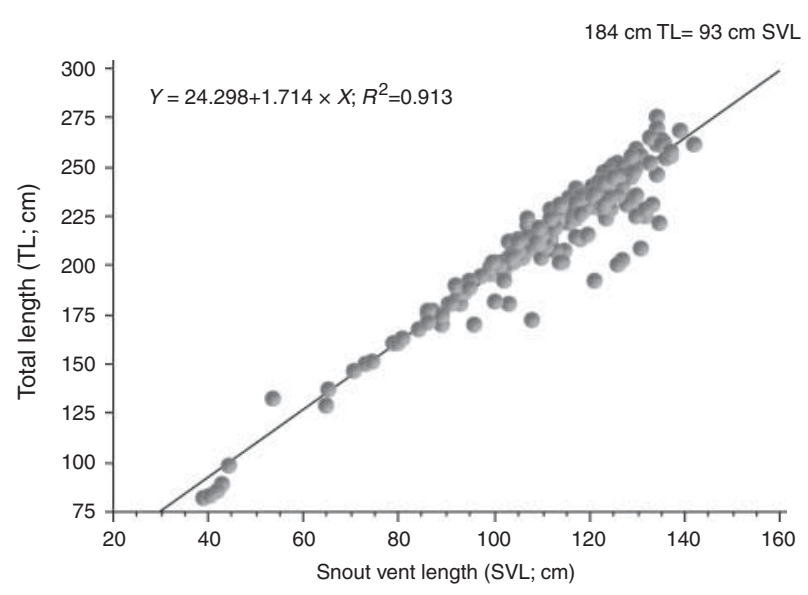

Figure 1 Simple regression of total length $(\mathrm{cm})$ vs snout vent length $(\mathrm{cm})$ in adult female American alligators from the Merritt Island National Wildlife Refuge.
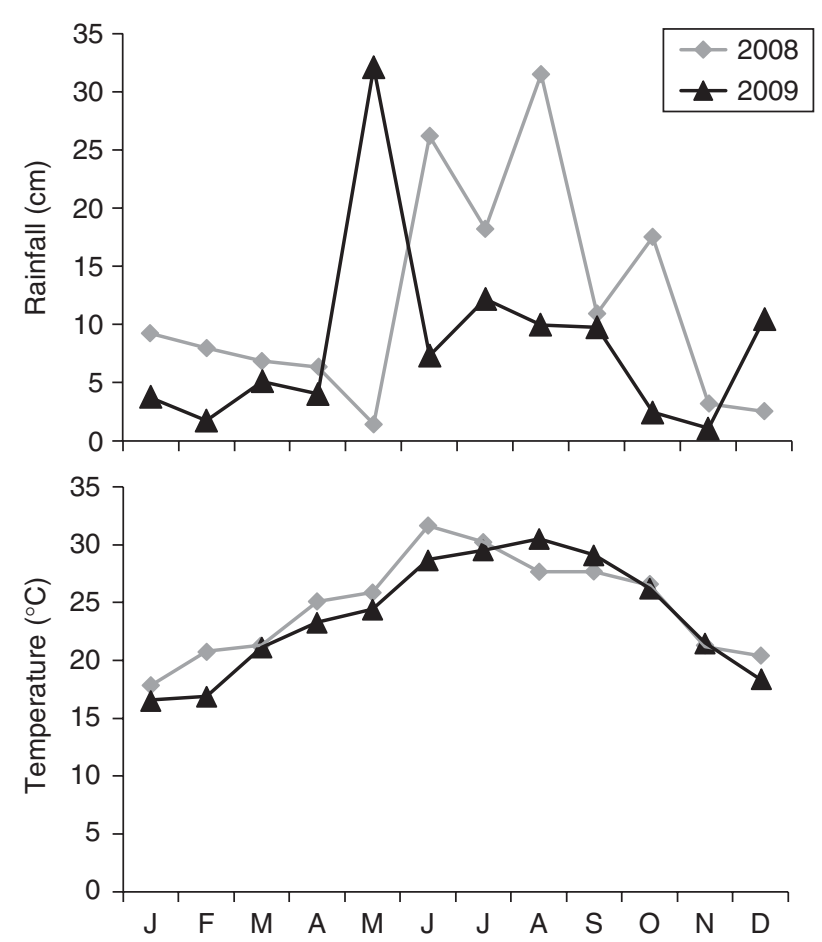

Figure 2 Average monthly temperature $\left({ }^{\circ} \mathrm{C}\right)$ and rainfall $(\mathrm{cm})$ for 2008 (gray line) and 2009 (black line) from the Merritt Island National Wildlife Refuge.

no significant differences in female size (TL or SVL) between months.

\section{$E_{2}, V T G$, and $P_{4}$}

Plasma concentrations of $E_{2}$ peaked in April (575 \pm $114 \mathrm{pg} / \mathrm{ml}$ ) and dropped gradually to a nadir in August $(119 \pm 18 \mathrm{pg} / \mathrm{ml})$ (Fig. 3). Plasma concentrations of VTG also peaked in April (5.4 \pm 1.7 relative $V T G)$ and dropped rapidly by July $(0.20 \pm 0.07$ relative VTG); plasma VTG concentrations then remained relatively stable throughout the year until March, when a noticeable but insignificant increase could be seen (Fig. 3). Plasma concentrations of $E_{2}$ and VTG were positively correlated (Fig. 4). Plasma concentrations of $\mathrm{P}_{4}$ were statistically similar throughout the year, with a noticeable but insignificant increase from March to April (Fig. 5). Patterns for $E_{2}, V T G$, and $P_{4}$ were similar between 2008 and 2009 during the breeding season.

\section{DHEA and testosterone}

Plasma concentrations of DHEA increased in June and peaked in July $(42 \pm 4 \mathrm{ng} / \mathrm{ml})$, with a precipitous decline in August (27 $\pm 3 \mathrm{ng} / \mathrm{ml}$ ) (Fig. 6). There was a slight increase in plasma DHEA in October $(32 \pm 4 \mathrm{ng} / \mathrm{ml})$ and a gradual decrease by December where plasma concentrations remained relatively stable throughout winter and spring. Patterns in plasma concentrations of 


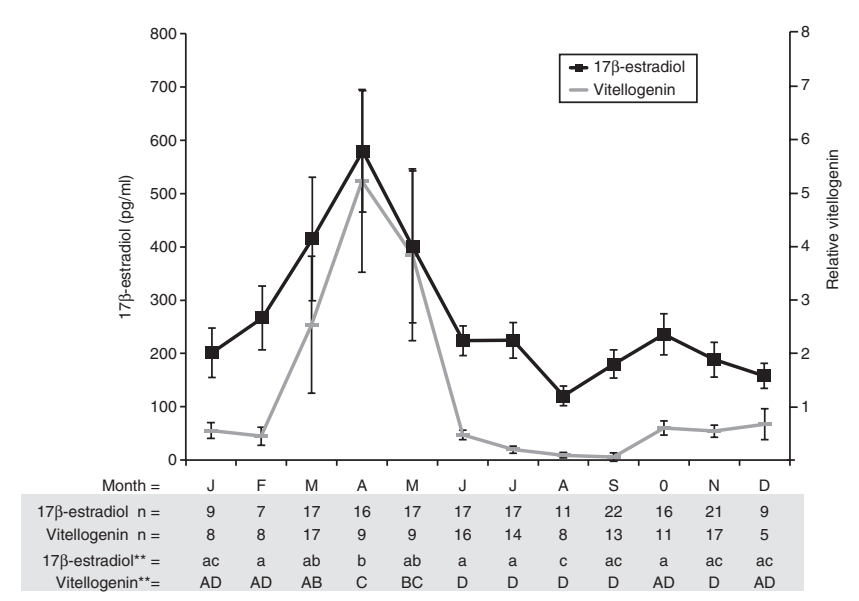

Figure 3 Monthly variation in mean ( \pm 1 S.E.M.) plasma $17 \beta$-estradiol $(\mathrm{pg} / \mathrm{ml})$ and relative vitellogenin concentration of adult female ( $\geq 93 \mathrm{~cm} \mathrm{SVL}$ ) American alligators from the Merritt Island National Wildlife Refuge collected between 2006 and 2010. ${ }^{* *}$ Months with different superscripts are significantly different $(P \geq 0.05) ; n$, numbers of sampled animals used in the analyses.

DHEA were similar between 2008 and 2009 during the breeding season.

Plasma testosterone concentrations showed a dramatic increase in May $(263 \pm 109 \mathrm{pg} / \mathrm{ml})$ and a rapid drop in June $(71 \pm 7 \mathrm{pg} / \mathrm{ml})$ where concentrations remained relatively constant throughout the remaining months (Fig. 7). Patterns in plasma testosterone concentrations were significantly different during the breeding season between 2008 and 2009, with an expected peak in May of 2008, but no peak in May of 2009 (Fig. 8). In addition, 2008 showed a significant increase in July $(277 \pm 122 \mathrm{pg} / \mathrm{ml})$, which decreased and was relatively constant for the remaining months. In 2009, plasma concentrations of testosterone were not significantly different between months.

\section{Discussion}

Adult female alligators from $\mathrm{MI}$ showed seasonal concentrations of plasma $E_{2}$ and testosterone that paralleled seasonal patterns reported in adult female alligators from other locales. Seasonal patterns in plasma $\mathrm{P}_{4}$ concentration, however, were distinctive from previously reported data in other regions (Guillette et al. 1997). This is the first study to show seasonal variation in plasma DHEA concentrations in a female crocodilian and is the most extensive assessment to date, both in terms of the range of hormones analyzed and the number of animals sampled, in a population of adult female American alligators.

As expected, plasma concentrations of VTG paralleled that of $E_{2}$, a pattern characteristic of most oviparous vertebrates (Figs 3 and 4; Ho 1987). Elevated plasma VTG concentrations are important for proper egg development, and plasma $E_{2}$ concentrations were sufficiently elevated to elicit hepatic VTG production. Plasma $E_{2}$ concentrations peaked in April, coincident with courtship and mating, and showed similar patterns to that observed in adult female alligators in other regions, including Florida's freshwater lakes and coastal Louisiana (Lance 1989, Guillette et al. 1997, Lance et al. 2009).

Unlike previously reported seasonal patterns for $\mathrm{P}_{4}$ in alligators from other regions, in which plasma $\mathrm{P}_{4}$ concentrations are lowest in April and then peak during oviposition in June (Lance 1989, Guillette et al. 1997, Lance et al. 2009), this pattern was not observed in MI females. Females in this study maintained relatively stable plasma $\mathrm{P}_{4}$ concentrations throughout the year, with a noticeable yet insignificant increase occurring between March and April. Concentrations of plasma $\mathrm{P}_{4}$ are considerably lower in this study than previous studies, which could highlight a unique difference in $\mathrm{MI}$ adult female alligator populations or could reflect differences in assay performance. Antibody specificity has improved greatly in recent years, and it is possible that in older studies, $\mathrm{P}_{4}$ antibodies with lower specificity could have bound with a wide range of progestins, resulting in seemingly higher $\mathrm{P}_{4}$ concentrations. Regardless, it is interesting that distinct seasonal patterns in plasma $\mathrm{P}_{4}$ concentrations were not observed in this study given that robust seasonal patterns have been shown not only in American alligators (Lance 1989, Guillette et al. 1997, Lance et al. 2009) but also in other reptiles as well as birds, which are closely related to archosaurs (Donham 1979, Amey \& Whittier 2000). Nile crocodiles (Crocodylus niloticus) do not show distinct seasonal patterns in plasma $\mathrm{P}_{4}$ concentrations, however, and show highly variable concentrations throughout the year in both reproductive and non-reproductive individuals (Kofron 1990).

Although there could be many explanations for the lack of seasonal variability in plasma $\mathrm{P}_{4}$ concentrations

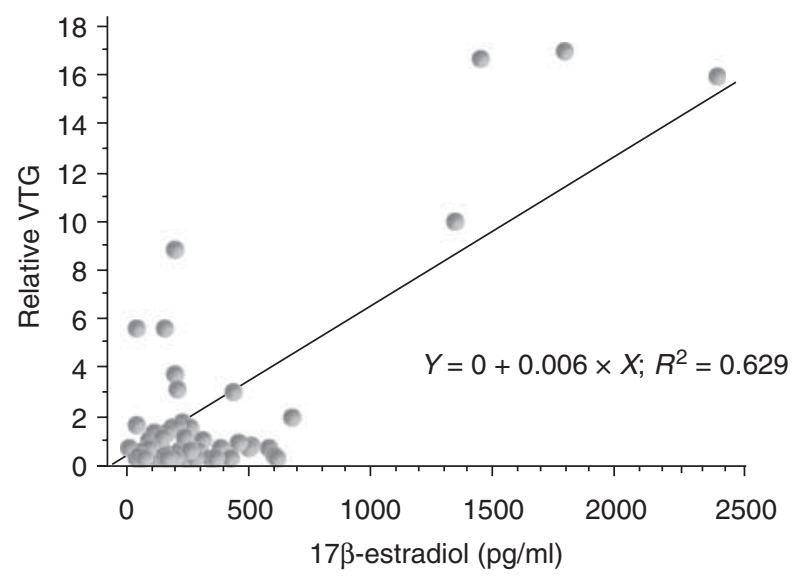

Figure 4 Simple regression of relative vitellogenin (VTG) vs plasma $17 \beta$-estradiol concentration in adult female American alligators from the Merritt Island National Wildlife Refuge. 


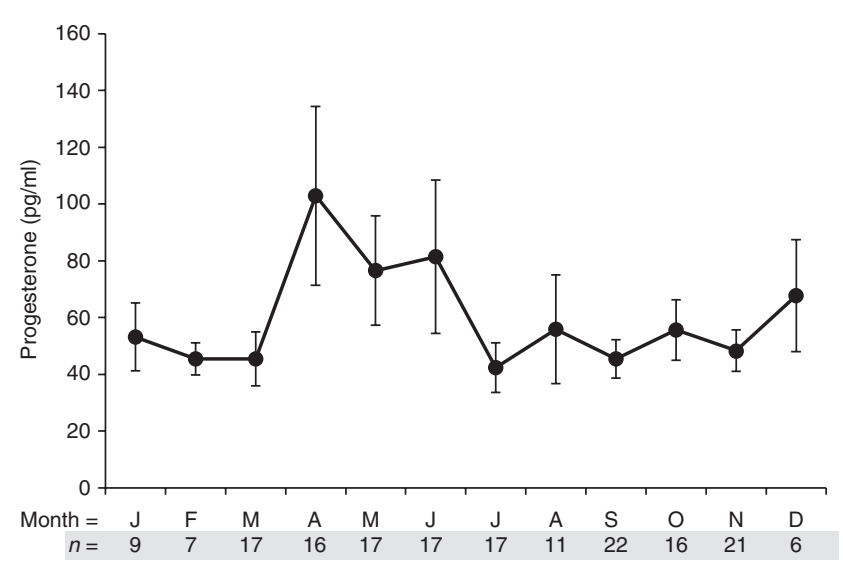

Figure 5 Monthly variation in mean ( \pm 1 S.E.M.) plasma progesterone $(\mathrm{pg} / \mathrm{ml})$ concentrations of adult female $(\geq 93 \mathrm{~cm} \mathrm{SVL})$ American alligators from the Merritt Island National Wildlife Refuge collected between 2006 and 2010. $n$, numbers of sampled animals used in the analyses.

in $\mathrm{MI}$ alligator populations vs those in other regions, there are three explanations that share scientific support and are particularly plausible.

First, alligators in $\mathrm{MI}$ consume a decidedly different diet than those in other locales, as indicated by gut content analyses showing greater percentages of marine prey, especially crustaceans, vs that of alligators from freshwater lakes, or even those of coastal Louisiana (Gabrey 2010, Nifong et al. 2012, Nifong \& Silliman 2013). Diet has been shown to alter hormone concentrations in a number of vertebrate models, including alligators. The production of thyroid hormones is reliant upon the availability of iodide, and it has been suggested that the abundance of dietary iodide in the marine prey of $\mathrm{MI}$ alligators could alter thyroid hormone concentrations and reduce the seasonal variation seen in alligators from other locales (Boggs et al. 2011). Diet has also been shown to alter concentrations of sex steroids in a variety of species, including reptiles (Cree et al. 1995, Lovern \& Adams 2008). Female green anole lizards (Anolis carolinensis) fed higher quality diets showed greater plasma testosterone concentrations than do females on standard or low-quality diets (Lovern \& Adams 2008) and produce eggs with elevated yolk testosterone concentrations as well (Warner et al. 2007). It is unclear what effect diet could have on plasma $\mathrm{P}_{4}$ concentrations in American alligators.

Secondly, MI is home to the Kennedy Space Center, and although heightened security in this area removes hunting, and even poaching pressures, stress-related effects associated with shuttle launches and other activities are unclear. Launches and other activities have led to concerns regarding elevated environmental concentrations of aluminum and other heavy metals (Bowden et al. 2012), as well chemicals such as polybrominated diphenyl ethers (PBDEs) used in flame retardants (Guillette \& Lowers, unpublished results). Although the influence of aluminum and PBDEs on plasma $\mathrm{P}_{4}$ concentrations in alligators is unknown, evidence in other vertebrates suggests possible effects. Subchronic exposures to aluminum resulted in reduced serum progestogen concentrations in Wistar rats (Alonso et al. 2010). Certain PBDEs have been shown to decrease $\mathrm{P}_{4}$ synthesis in mouse Leydig tumor cells (Han et al. 2012) while other PBDEs have been shown to increase $\mathrm{P}_{4}$ synthesis in the ovarian follicles of pigs (Karpeta \& Gregoraszczuk 2010). Proposed mechanisms of action in the latter study include modulation of key steroidogenic genes, many of which are highly conserved among vertebrates (Karpeta et al. 2011).

Thirdly, it is difficult to determine which of the females that were sampled in this study were reproductively active. It is possible that in June, the time period during which other populations of alligators have shown peaks in plasma $\mathrm{P}_{4}$ concentrations, very few reproductively active alligators were captured in this study, reducing the ability to observe expected patterns.

Plasma DHEA peaked in June and July, around the time of oviposition, and then decreased in August and remained relatively constant for the rest of the year, except for a slight increase in October. Concentrations of plasma DHEA are an order of magnitude greater than plasma testosterone concentrations and are similar to those reported for adult male alligators (Hamlin et al. 2011). This is the first study to show the presence of DHEA in a female crocodilian, and seasonal changes in plasma concentrations coincident with reproductive activity suggest a reproductive and/or behavioral role. Although DHEA has been shown to play a variety of beneficial roles in humans and laboratory animals, its role in maintaining non-breeding aggression has been the focus of most wildlife studies (Poisbleau et al. 2009).

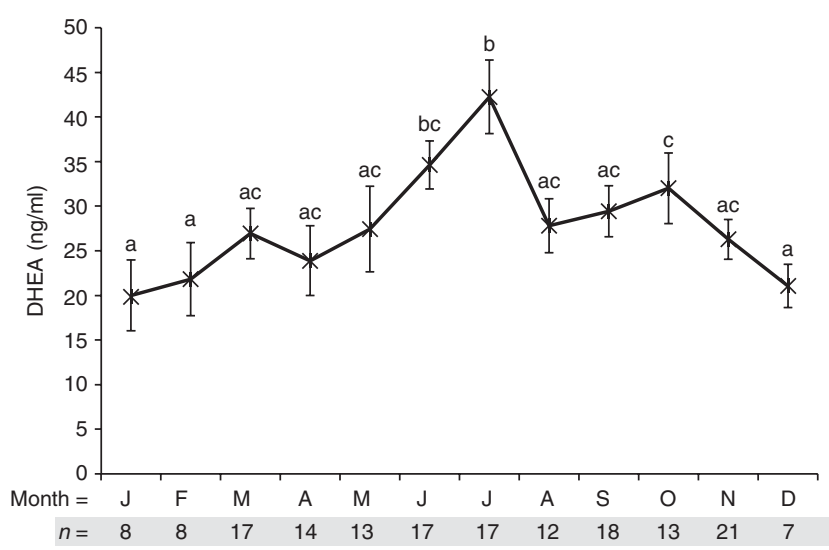

Figure 6 Monthly variation in mean ( \pm 1 S.E.M.) plasma DHEA concentration of adult female ( $\geq 93 \mathrm{~cm}$ SVL) American alligators from the Merritt Island National Wildlife Refuge collected between 2006 and 2010. Months with the same superscript are not significantly different $(P \geq 0.05)$ within each size class; $n$, numbers of sampled animals used in the analyses. 


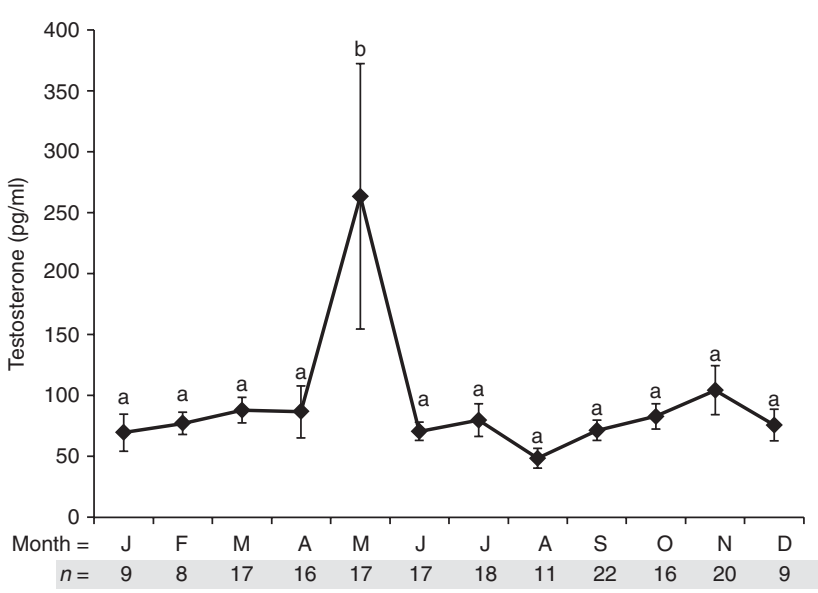

Figure 7 Monthly variation in mean ( \pm 1 S.E.M.) plasma testosterone $(\mathrm{pg} / \mathrm{ml})$ concentration of adult female ( $\geq 93 \mathrm{~cm} \mathrm{SVL}$ ) American alligators from the Merritt Island National Wildlife Refuge collected between 2006 and 2010. Months with the same superscript are not significantly different $(P \geq 0.05)$ within each size class; $n$, numbers of sampled animals used in the analyses.

In adult male alligators, plasma DHEA concentrations peak during periods of intense breeding and courtship, but in females, plasma DHEA concentration was shown to peak during oviposition and early nest guarding. Given that plasma DHEA concentrations in this study were among the highest levels of sex steroids reported in a female crocodilian to date, more work should be conducted to determine DHEA's role in the biology of American alligators (Guillette et al. 1997, Lance et al. 2009).

Previous studies in adult female alligators have shown plasma testosterone concentrations to peak in May, coincident with courtship and mating. Alligators of both sexes display complex behaviors including bellowing (Garrick \& Lang 1977, Vliet 1989), and although the role of testosterone in alligator behavior has not yet been studied, testosterone has been shown to affect behavior in a variety of vertebrates, including reptiles and birds (Lindzey \& Crews 1986, Lynn 2008). Interestingly, this study showed an expected peak in plasma testosterone concentration in May of 2008, but no peak in 2009. Surveys of alligator nests in MI show 2009 to be an exceptionally poor breeding year, with few nests located despite increased efforts (Lowers, unpublished data). If plasma testosterone concentration correlates with breeding success, this could support the possibility that only non-reproductively active females were captured in May of 2009. In addition, the lack of females captured in 2009 showing the expected peak in plasma testosterone concentration in summer as well would indicate that very few females were reproductively active that year.

Although plasma testosterone concentration in female alligators was markedly different between years that showed normal vs poor nest abundance, and presumably mating success, the patterns of other hormones analyzed in this study were not significantly different during the breeding season between years. Therefore, it is possible that a spike in plasma testosterone concentration is necessary for successful breeding or perhaps increases as a result of successful breeding, while plasma $\mathrm{E}_{2}$ and DHEA concentrations could show seasonal patterns regardless of whether successful breeding takes place.

The reasons for the variation in nest abundance and altered seasonal patterns of plasma testosterone concentration in May between 2008 and 2009 in Ml are unclear. Although water temperatures were similar for the month of May in 2008 and 2009 (Fig. 3), rainfall varied considerably, with $1.4 \mathrm{~cm}$ in 2008 vs $32.1 \mathrm{~cm}$ in 2009 . Joanen \& McNease (1989) found increased nest abundance during periods when water levels were above average but reduced nest abundance if water levels increased to the point of extreme flooding. Conversely, they found nest abundance was lowest during periods of drought. Although rainfall was markedly different for the month of May, cumulative rainfall for January-July was nearly the same for 2008 and 2009. It is unclear what effect rainfall has on alligator courtship or breeding in MI, however, increased rainfall in May could presumably lead to a reduction in viable nest sites, which could alter the female's decisions to mate. Although highly speculative until this phenomenon is confirmed over multiple years in $\mathrm{MI}$, it is nonetheless an interesting observation. In male alligators, size favors social order, and although smaller adult males are capable of breeding, they show a different pattern of plasma testosterone concentration than larger males. In smaller adult males, instead of peaking midseason as it does in larger males, plasma testosterone concentrations drop off precipitously to basal levels. Given that these smaller males are physiologically capable of breeding, it is possible that this drop in

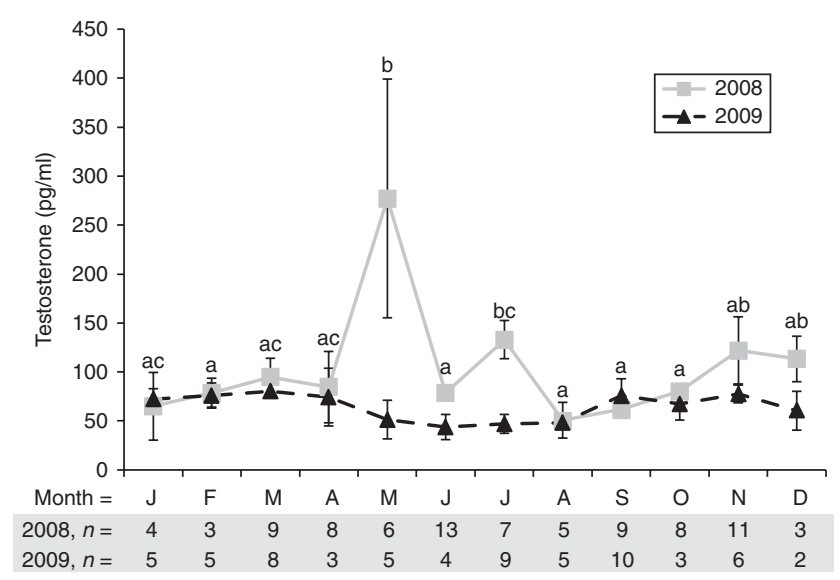

Figure 8 Monthly variation in mean ( \pm 1 S.E.M.) plasma testosterone concentration for 2008 and 2009 of adult female ( $\geq 93 \mathrm{~cm} \mathrm{SVL}$ ) alligators from the Merritt Island National Wildlife Refuge. Months with the same superscript are not significantly different within each year; $n$, numbers of sampled animals used in the analyses. 
testosterone could be driven by social cues. It is then conceivable that a female could refrain from breeding due to environmental cues as well.

\section{Declaration of interest}

The authors declare that there is no conflict of interest that could be perceived as prejudicing the impartiality of the research reported.

\section{Funding}

This study was supported in part by grants-in-aid for scientific research (C) (grant number 21510068) (Y Ohta) and scientific research (B) (grant number 24370029) (T Iguchi and S Miyagawa) from the Ministry of Education, Culture, Sports, Science, and Technology, Japan.

\section{Acknowledgements}

Appreciation is gratefully extended to the following individuals for assistance in field and/or data collection; Doug Scheidt, Carlton Hall, Stephanie Weiss, Matthew Guillette, Shannon Gann, Carly Garreau, Eric Reyier, Karen Holloway-Adkins, Jim Lyons, Mike Legare, Joe Benjamin, Rebecca Bolt, Mark Mercadante, John Shaffer, and Lynne Phillips.

\section{References}

Ahmed SA \& Talal N 1990 Sex hormones and the immune system. 2. Animal data. Baillière's Clinical Rheumatology 4 13-31. (doi:10.1016/S09503579(05)80241-9)

Alonso V, Linares V, Belles M, Albina ML, Pujol A, Domingo JL \& Sanchez DJ 2010 Effects of BDE-99 on hormone homeostasis and biochemical parameters in adult male rats. Food and Chemical Toxicology 48 2206-2211. (doi:10.1016/j.fct.2010.05.048)

Amano H, Fujita T, Hiramatsu N, Shimizu M, Sawaguch S, latsubara T, Kagawa H, Nagae M, Sullivan CV \& Hara A 2007 Egg yolk proteins in gray mullet (Mugil cephalus): purification and classification of multiple lipovitellins and other vitellogenin-derived yolk proteins and molecular cloning of the parent vitellogenin genes. Journal of Experimental Zoology. Part A, Ecological Genetics and Physiology 307A 324-341. (doi:10.1002/jez.388)

Amey AP \& Whittier JM 2000 Seasonal patterns of plasma steroid hormones in males and females of the bearded dragon lizard, Pogona barbata. General and Comparative Endocrinology 117 335-342. (doi:10.1006/ gcen.2000.7426)

Ando S, Canonaco M, Beraldi E, Valenti A, Maggiolini M, Piro A, Tavolaro R \& Fulgheri FD 1988 The evaluation of androgen circulating levels following castration in adult male rats. Experimental and Clinical Endocrinology 91 311-318. (doi:10.1055/s-0029-1210763)

Ando S, Ciarcia G, Panno ML, Imbrogno E, Tarantino G, Buffone M, Beraldi E, Angelini F \& Botte V 1992 Sex steroids levels in the plasma and testis during the reproductive-cycle of lizard Polarcis-sicula-sicula Raf. General and Comparative Endocrinology 85 1-7. (doi:10.1016/00166480(92)90165-G)

Balthazart J 2010 Behavioral implications of rapid changes in steroid production action in the brain [Commentary on Pradhan DS, Newman AEM, Wacker DW, Wingfield JC, Schlinger BA and Soma KK: Aggressive interactions rapidly increase androgen synthesis in the brain during the non-breeding season]. Hormones and Behavior 57 375-378. (doi:10.1016/j.yhbeh.2010.02.003)

Boggs ASP, Hamlin HJ, Lowers RH \& Guillette LJ 2011 Seasonal variation in plasma thyroid hormone concentrations in coastal versus inland populations of juvenile American alligators (Alligator mississippiensis): influence of plasma iodide concentrations. General and Comparative Endocrinology 174 362-369. (doi:10.1016/j.ygcen.2011.09.014)

Boonstra R, Lane JE, Boutin S, Bradley A, Desantis L, Newman AEM \& Soma KK 2008 Plasma DHEA levels in wild, territorial red squirrels: seasonal variation and effect of ACTH. General and Comparative Endocrinology 158 61-67. (doi:10.1016/j.ygcen.2008.05.004)

Bowden JA, Nocito BA, Lowers RH, Guillette LJ, Williams KR \& Young VY 2012 Environmental indicators of metal pollution and emission: an experiment for the instrumental analysis laboratory. Journal of Chemical Education 89 1057-1060. (doi:10.1021/ed200490y)

Brasfield SM, Talent LG \& Janz DM 2008 Reproductive and thyroid hormone profiles in captive Western fence lizards (Sceloporus occidentalis) after a period of brumation. Zoo Biology 27 36-48. (doi:10.1002/zoo.20159)

Chin EH, Shah AH, Schmidt KL, Sheldon LD, Love OP \& Soma KK 2008 Sex differences in DHEA and estradiol during development in a wild songbird: jugular versus brachial plasma. Hormones and Behavior $\mathbf{5 4}$ 194-202. (doi:10.1016/j.yhbeh.2008.02.014)

Conley AJ, Pattison JC \& Bird IM 2004 Variations in adrenal androgen production among (nonhuman) primates. Seminars in Reproductive Medicine 22 311-326.

Cree A, Daugherty CH \& Hay JM 1995 Reproduction of rare New Zealand reptile, the Tuatara sphenodon-punctatus, on rat-free and rat-inhabited islands. Conservation Biology 9 373-383. (doi:10.1046/j.1523-1739. 1995.9020373.x)

Croll RP \& Wang C 2007 Possible roles of sex steroids in the control of reproduction in bivalve molluscs. Aquaculture 272 76-86. (doi:10.1016/ j.aquaculture.2007.06.031)

Daynes RA \& Jones DC 2002 Emerging roles of PPARs in inflammation and immunity. Nature Reviews. Immunology 2 748-759. (doi:10.1038/ nri912)

Donham RS 1979 Annual cycle of plasma luteinizing-hormone and sexhormones in male and female mallards (Anas platyrhynchos). Biology of Reproduction 21 1273-1285. (doi:10.1095/biolreprod21.5.1273)

Edwards A \& Jones SM 2001 Changes in plasma progesterone, estrogen, and testosterone concentrations throughout the reproductive cycle in female viviparous blue-tongued skinks, Tiliqua nigrolutea (Scincidae), in Tasmania. General and Comparative Endocrinology 122 260-269. (doi:10.1006/gcen.2001.7634)

Gabrey SW 2010 Demographic and geographic variation in food habits of American alligators (Alligator mississippiensis) in Louisiana. Herpetological Conservation and Biology 5 241-250.

Garrick LD \& Lang JW 1977 Social signals and behaviors of adult alligators and crocodiles. American Zoologist 17 225-239.

Garstka WR, Cooper WE, Wasmund KW \& Lovich JE 1991 Male sex steroids and hormonal control of male courtship behavior in the yellowbellied slider turtle, Trachemys scripta. Comparative Biochemistry and Physiology. Part A, Physiology 98A 271-280. (doi:10.1016/03009629(91)90532-H)

Gleicher N \& Barad DH 2011 Dehydroepiandrosterone (DHEA) supplementation in diminished ovarian reserve (DOR). Reproductive Biology and Endocrinology 9 67. (doi:10.1186/1477-7827-9-67)

Goodson JL, Saldanha CJ, Hahn TP \& Soma KK 2005 Recent advances in behavioral neuroendocrinology: insights from studies on birds. Hormones and Behavior 48 461-473. (doi:10.1016/j.yhbeh.2005.04.005)

Grimble RF 2001 Symposium on 'evidence-based nutrition' - nutritional modulation of immune function. Proceedings of the Nutrition Society $\mathbf{6 0}$ 389-397. (doi:10.1079/PNS2001102)

Groombridge B 1987 The distribution and status of world crocodilians. In Wildlife Management: Crocodiles and Alligators, pp. 9-22. Eds GJW Webb, SC Manolis \& PJ Whitehead. New South Wales: Surrey Beatty \& Sons Pty Limited in association with the Conservation Commission of the Northern Territory.

Guillette LJ, Woodward AR, Crain DA, Masson GR, Palmer BD, Cox MC, Qui YX \& Orlando EF 1997 The reproductive cycle of the female American alligator (Alligator mississippiensis). General and Comparative Endocrinology 108 87-101. (doi:10.1006/gcen.1997.6953)

Hamlin HJ, Lowers RH \& Guillette LJ Jr 2011 Seasonal androgen cycles in adult male American alligators (Alligator mississippiensis) from a barrier island population. Biology of Reproduction 85 1108-1113. (doi:10.1095/biolreprod.111.092692) 
Han XM, Tang R, Chen XJ, Xu B, Qin YF, Wu W, Hu YH, Xu B, Song L, Xia YK et al. 2012 2,2',4,4'-Tetrabromodiphenyl ether (BDE-47) decreases progesterone synthesis through CAMP-PKA pathway and P450scc downregulation in mouse Leydig tumor cells. Toxicology 302 44-50. (doi:10.1016/j.tox.2012.07.010)

Hiramatsu N \& Hara A 1996 Relationship between vitellogenin and its related egg yolk proteins in Sakhalin taimen (Hucho perryi). Comparative Biochemistry and Physiology. Part A, Physiology 115A 243-251. (doi:10. 1016/0300-9629(96)00055-2)

Ho SM 1987 Endocrinology of vitellogenesis. In Hormones and Reproduction in Fishes, Amphibians and Reptiles, pp 145-169. New York, London: Plenum Press.

Ho SM, Kleis S, McPherson R, Heisermann GJ \& Callard IP 1982 Regulation of vitellogenesis in reptiles. Herpetologica 38 40-50.

Joanen T \& McNease LL 1989 Ecology and physiology of nesting and early development of the American alligator. American Zoologist 29 987-998.

Jones SM 2011 Hormonal regulation of ovarian function in reptiles. In Hormones and Reproduction of Vertebrates, pp 89-115. Eds DO Norris, KH Lopez. San Diego, CA, USA: Elsevier Academic Press.

Jones SM \& Swain R 1996 Annual reproductive cycle and annual cycles of reproductive hormones in plasma of female Niveoscincus metallicus (Scincidae) from Tasmania. Journal of Herpetology 30 140-146. (doi:10.2307/1565504)

Karpeta A \& Gregoraszczuk E 2010 Mixture of dominant PBDE congeners (BDE-47, -99, -100 and -209) at levels noted in human blood dramatically enhances progesterone secretion by ovarian follicles. Endocrine Regulations 44 49-55. (doi:10.4149/endo_2010_02_49)

Karpeta A, Rak-Mardyla A, Jerzak J \& Gregoraszczuk EL 2011 Congenerspecific action of PBDEs on steroid secretion, CYP17, 17ß-HSD and CYP19 activity and protein expression in porcine ovarian follicles. Toxicology Letters 206 258-263. (doi:10.1016/j.toxlet.2011.08.005)

Klein SL 2000 Hormones and mating system affect sex and species differences in immune function among vertebrates. Behavioural Processes 51 149-166. (doi:10.1016/S0376-6357(00)00125-X)

Kofron CP 1990 The reproductive cycle of the Nile crocodile (Crocodylus niloticus). Journal of Zoology 221 477-488. (doi:10.1111/j.1469-7998. 1990.tb04014.x)

Labrie F, Luu-The V, Belanger A, Lin SX, Simard J, Pelletier G \& Labrie C 2005 Is dehydroepiandrosterone a hormone? Journal of Endocrinology 187 169-196. (doi:10.1677/joe.1.06264)

Lance VA 1989 Reproductive cycle of the American alligator. American Zoologist 29 999-1018.

Lance VA, Rostal DC, Elsey RM \& Trosclair PL III 2009 Ultrasonography of reproductive structures and hormonal correlates of follicular development in female American alligators, Alligator mississippiensis, in southwest Louisiana. General and Comparative Endocrinology 162 251-256. (doi:10.1016/j.ygcen.2009.03.021)

Lindzey J \& Crews D 1986 Hormonal control of courtship and copulatory behavior in male Cnemidophorus inornatus, a direct sexual ancestor of unisexual, parthenogenetic lizard. General and Comparative Endocrinology 64 411-418. (doi:10.1016/0016-6480(86)90077-8)

Loria RM \& Ben-Nathan D 2011 Protective effects of DHEA and AED against viral, bacterial and parasitic infections. Israel Journal of Veterinary Medicine 66 119-129.

Lovern MB \& Adams AL 2008 The effects of diet on plasma and yolk steroids in lizards (Anolis carolinensis). Integrative and Comparative Biology $\mathbf{4 8}$ 428-436. (doi:10.1093/icb/icn058)

Lynn SE 2008 Behavioral insensitivity to testosterone: why and how does testosterone alter paternal and aggressive behavior in some avian species but not others? General and Comparative Endocrinology 157 233-240. (doi:10.1016/j.ygcen.2008.05.009)

Maninger N, Wolkowitz OM, Reus VI, Epel ES \& Mellon SH 2009 Neurobiological and neuropsychiatric effects of dehydroepiandrosterone (DHEA) and DHEA sulfate (DHEAS). Frontiers in Neuroendocrinology 30 65-91. (doi:10.1016/j.yfrne.2008.11.002)

McEwen BS 1981 Neural gonadal-steroid actions. Science 211 1303-1311. (doi:10.1126/science.6259728)

Miller L \& Hunt JS 1996 Sex steroid hormones and macrophage function. Life Sciences 59 1-14. (doi:10.1016/0024-3205(96)00122-1)

Milnes MR, Bryan TA, Medina JG, Gunderson MP \& Guillette LJ 2005 Developmental alterations as a result of in ovo exposure to the pesticide metabolite $\mathrm{p}, \mathrm{p}^{\prime}$-DDE in Alligator mississippiensis. General and Comparative Endocrinology 144 257-263. (doi:10.1016/j.ygcen. 2005.06.013)

Moller AP, Garamszegi LZ, Gil D, Hurtrez-Bousses S \& Eens M 2005 Correlated evolution of male and female testosterone profiles in birds and its consequences. Behavioral Ecology and Sociobiology $\mathbf{5 8}$ 534-544. (doi:10.1007/s00265-005-0962-2)

Nifong JC \& Silliman BR 2013 Impacts of a large-bodied, apex predator (Alligator mississippiensis Daudin 1801) on salt marsh food webs. Journal of Experimental Marine Biology and Ecology 440 185-191. (doi:10.1016/j.jembe.2013.01.002)

Nifong JC, Rosenblatt AE, Johnson NA, Barichivich W, Silliman BR \& Heithaus MR 2012 American alligator digestion rate of blue crabs and its implications for stomach contents analysis. Copeia 2012 419-423. (doi:10.1643/CE-11-177)

Ott JA, Mendonca MT, Guyer C \& Michener WK 2000 Seasonal changes in sex and adrenal steroid hormones of gopher tortoises (Gopherus polyphemus). General and Comparative Endocrinology 117 299-312. (doi:10.1006/gcen.1999.7419)

Pinxten R, De Ridder E, De Cock M \& Eens M 2003 Castration does not decrease nonreproductive aggression in yearling male European starlings (Sturnus vulgaris). Hormones and Behavior 43 394-401. (doi:10.1016/ S0018-506X(03)00012-6)

Poisbleau M, Lacroix A \& Chastel O 2009 DHEA levels and social dominance relationships in wintering brent geese (Branta bernicla bernicla). Behavioural Processes 80 99-103. (doi:10REF59=10.1016/ j.ygcen.2007.10.005)

Smith CF, Schuett GW \& Schwenk K 2010 Relationship of plasma sex steroids to the mating season of copperheads at the north-eastern extreme of their range. Journal of Zoology 280 362-370. (doi:10.1111/ j.1469-7998.2009REF61 =10.1080/03602530600569877)

Soma KK 2006 Testosterone and aggression: Berthold, birds and beyond. Journal of Neuroendocrinology 18 543-551. (doi:10.1111/j.1365-2826. 2006.01440.x)

Vliet KA 1989 Social displays of the American alligator (Alligator mississippiensis). American Zoologist 29 1019-1031.

Wack CL, Fox SF, Hellgren EC \& Lovern MB 2008 Effects of sex, age, and season on plasma steroids in free-ranging Texas horned lizards (Phrynosoma cornutum). General and Comparative Endocrinology 155 589-596. (doi:10.1016/j.ygcen.2007.10.REF66=10. 1016/j.physbeh.2004.08.021)

Warner DA, Lovern MB \& Shine R 2007 Maternal nutrition affects reproductive output and sex allocation in a lizard with environmental sex determination. Proceedings of the Royal Society of London. Series B, Biological Sciences 274B 883-890. (doi:10.1098/rspb.2006.0105)

Webb SJ, Geoghegan TE \& Prough RA 2006 The biological actions of dehydroepiandrosterone involves multiple receptors. Drug Metabolism Reviews 38 89-116. (doi:10.1080/03602530600569877)

Whittier JM \& Crews D 1987 Seasonal reproduction: patterns and control. In Hormones and Reproduction in Fishes, Amphibians, and Reptiles, pp 385-409. Eds DO Norris \& RE Jones. New York \& London: Plenum Press.

Widstrom RL \& Dillon JS 2004 Is there a receptor for dehydroepiandrosterone or dehydroepiandrosterone sulfate? Seminars in Reproductive Medicine 22 289-298. (doi:10.1055/s-2004-861546)

Wilder RL 1995 Neuroendocrine-immune system interactions and autoimmunity. Annual Review of Immunology 13 307-338. (doi:10. 1146/annurev.iy.13.040195.001515)

Wingfield JC \& Hahn TP 1994 Testosterone and territorial behavior in sedentary and migratory sparrows. Animal Behaviour 47 77-89. (doi:10. 1006/anbe.1994.1009)

Woolley SC, Sakata JT \& Crews D 2004 Evolutionary insights into the regulation of courtship behavior in male amphibians and reptiles. Physiology \& Behavior 83 347-360. (doi:10.1016/j.physbeh.2004. 08.021)

Received 20 January 2014

First decision 13 February 2014

Revised manuscript received 24 February 2014

Accepted 6 March 2014 